\title{
Case Study: Reflection of COVID-19 on Teaching Physics for Undergraduate Students
}

\author{
M. A. Zaki Ewiss \\ Department of Physics, Faculty of Science, Cairo University, Giza, Egypt.
}

How to cite this paper: M. A. Zaki Ewiss. (2020). Case Study: Reflection of COVID-19 on Teaching Physics for Undergraduate Students. The Educational Review, USA, 4(12), 211-218. DOI: $10.26855 /$ er.2020.12.001

Received: October 19, 2020

Accepted: November 16, 2020

Published: December 2, 2020

Corresponding author: M. A. Zaki Ewiss, Department of Physics, Faculty of Science, Cairo University, Giza, Egypt.

Email: mzewiss@cu.edu.eg

\begin{abstract}
The case study presented in this report provides information on the challenges of teaching physics for undergraduate students. We discuss the physics teaching method before and during the spread of COVID-19. Within the text, we explored the following topics: (1) Education before COVID-19; (2) The study problems in physics; (3) The face to face teaching methods; (4) Why is physics necessary for life? (5) Physics is associated with human thought; (6) Effective physics teaching skills; (7) Evaluation and assignments; (8) Characteristics of physics teaching skills; (9) Teaching physics and digital technology; (10) Challenges of the physics quality teaching during COVID-19.
\end{abstract}

\section{Keywords}

Physics Education, Digital Education, Teaching Method, Online Teaching

\section{Introduction}

Beginning of all, traditional work in the labour market differed in various fields (ESC-Comission, 2011; Field, 2010; Pellegrino \& Hilton, 2012). The job creation became dependent on acquiring skills and creating the knowledge necessary to achieve the quality of outputs of companies and organizations. Successful people increasingly expect to be able to:

- Live and work in the global labour market in any country,

- Travel as often as they like, for as long as they like,

- Improving their learning skills all the time,

- Working to increase their monthly income depends on their abilities and efficient creativity in job performance,

- Willingness to work in a team on an international level,

- Outsource things they don't like doing,

- Choose their hours and office.

It is worth noting that the modern methods of learning in the twenty-first century have assisted in achieving new society's perception of employment in different fields.

\subsection{I am a physicist}

In 1968, after I finished high school, my parent wanted me to graduate from the faculty of Engineering. On the contrary, from the beginning, my interest was to study physics and to be a physicist. Thank God, I succeeded to study my favour field of measure physics at the Faculty of Science, Cairo University in Egypt. In 1973, I obtained my B.Sc degree with distinction and I became a demonstrator at the same department. It was not easy to study all subjects and to cover much knowledge in both the classical and the advanced courses. At that time, many of the faculty members studied abroad mainly in Europe and obtained their PhD. Those staff members skilled in teaching, and we were interested 
in the topics they taught.

During my early years at the university, I was studious. My colleagues always asked me how to understand the nature and applications of physics in life, how somebody can study and prepared for exams in a short period. I was aware of the difficulties and advised my students to do the following homework:

1. Summarizing the physical theories with its laws of each topic in the form of points so that the summary does not exceed two pages,

2. Solving some issues on each theoretical law of the textbook or from different scientific sources. In this way, these laws follow in the mind of the student in an organized manner,

3. In case if somebody forgets some points, he can remember them more with more focus, and he must keep the summary until Needed.

Many students had a problem of lack of focus, and they cannot understand the teacher and solve the issues that require them in homework (Freedman, 1996). To avoid mix things up the students must focus ideas in their mind in an orderly manner, and solve questions of all the issues of previous examinations conducted before (Banik et al., 2013). So that, the exams becomes routine for them. The problems solving in physics is that it uses mathematics. After reading the question for the first time, one must arrange the data, determine what is required, write the laws needed to solve the problem and replace the values in the question. If some results do not exist with the data, he tries to find them using previous laws and make up for them in the mathematical relationship to get the solution. One must read the textbook and save the definitions and the mathematical laws from being able to solve the physical issues. It was essential to solve difficult examples more than once and compare the solution to the book solution. The steps to resolve matters must be understood not preserved, because the issues are different, and conservation leads to the wrong resolution of issues (Bell, 2016; Calvin, 2013; Finkelstein, 2004).

In the practical physics course, the student must review the way that the scientific equipment works and understand their functions, uses, graphs, and mathematical laws. The studies cover evidence, conclusions and experimental results. At that time, the student always needed to study the physics pen, notebook, and a calculator (Gutulo \& Tekello, 2015; Redish \& Steinberg, 1999).

\section{Why is physics necessary for life?}

When we describe the physical properties of the material, we do not mean the character of absolute perfection. Still, we suggest that this material tries to reach perfection by studying in-depth all the significant and partial theories associated with it so that a set of complete laws of events that occur around us and to reach this status as one of the essential aspirations of physicists. However, this may be a hit of luck and some fantasy (White, 2019; Goldenfeld \& Woese, 2011).

During the period 1975 to 1985, fortunately, I worked and studied at the Free University of Amsterdam in the Netherlands. I obtained my Doctoral and PhD degrees in the field of laser spectroscopy from the same Institute. I lived in a very healthy academic environment. In the Netherlands, the higher education system characterized by the following:

- The transition towards the future managed carefully and reasonably by the government so that it is not changed or destabilized;

- $\quad$ Every department had its academic freedoms and developed new patterns of autonomy;

- The higher education sector met the economy's needs in terms of people, training, research, and technology;

- $\quad$ Each university maximized its values, adopt innovators and create \& apply knowledge for the benefit of all;

- The role of universities identified in educating students to live life to the fullest, by acquiring skills, promoting meditation, imagination, and creativity, and contributing to community building;

- Every department must identify elements of strength and excellence in teaching and access to low participation groups;

- Exact plans for scientific research were made to create new knowledge and link them to the local and international economic development while providing clear opportunities for students to progress;

- $\quad$ Nurturing and encouraging student talent in various fields;

- The faculty introduces new methods of study and offer courses that meet the needs of students;

- The education system provided the opportunity for all those who can benefit from it, and determined the sufficient number of qualified staff and administrators to achieve the required tasks;

- Strengthening the management of educational institutions and the wise of leadership, which accomplished the objectives of the institution and improve the quality education and training programs with the implement of the precision plans; 
- $\quad$ Funding resources vary in colleges and departments through partnership research projects with the industry sector.

\subsection{Physics is associated with human thought}

I learned that physics has a special place in human thought because the different branches of human knowledge influence it. So it had all-time a vital role and a decisive impact in various fields of knowledge and science, such as mathematics, philosophy, biology and chemistry. It created a range of developments in the medical and technical sectors including, the advances made in the concept of electromagnetic, which led to the widespread use of machines, instruments and electrical devices, such as computers and television. The applications of thermodynamics led to a spectacular development in modern transport and engines. The equipment used to study various cosmic phenomena based on physical quantum mechanics such as the electron microscope and laser devices. This equipment led to the study of the atom and the emergence biological cells that used in the treatment and diagnosis of various cancers, Ball reported on the strangling between the human mind and quantum physics (Ball, 2017).

To understand physics, the student must first realize that it takes a lot of effort. He needs to learn a lot of different things in the fields of natural sciences, computers, engineering, etc. so that he can understand physical theories and learn about their existing applications. Mathematics is one of the essential things about physics. One needed to understand the mastery of mathematics such as the real number set, (the set of compound numbers), linear algebra (the space of vectors, arrays, etc.), calculus (limits and sequences), and the differential equations of different types.

We noted that the need for these mathematical skills arises at different stages in one's physics study, from primary school to advanced university levels. The question is, how to study and understand physics? In the beginning, we must begin to remember concepts and laws. Recently, Pawlak et al. (2020) introduced in detail a learning assistant approach to teaching computational physics problems (Pawlak et al., 2020).

Complex physical rules usually adopted by more specific and more perceptible laws using mathematics. So it is necessary to understand the mathematics and the simple parts that make up the law; in other words, to understand a theory, we must understand how to derive it (not save it). Still, if the law is empirical, the student must understand the experiment. It is also unnecessary to preserve the physical constants. Yet, at least one must know a way to reach them, whether through the Internet or books, but in the case of examinations, if the constants not given, they must be preserved, in addition to the importance of understanding the logic in mathematics and not keeping it (Chassy \& Jones, 2019).

It is worth to note that one will remember the constants and laws when used continuously, as the process of binding will become easier. Students must learn to solve many physical issues that contain many ideas; this will help them to understand the theory more, and linking the results of the resolution of these issues, as well as the effects of the approach with applications from real life in addition to images and shapes. It leads to a further consolidation of the concept, and this linkage will be easy to do when solving many physical issues and problems.

I taught the students how to solve the problem of physical issue. The steps are summarized as follows:

1. Understanding what the problem is.

2. One must describe the problem through related topics.

3. One must develop a plan to solve the problem.

4. To apply the proposed solution of the plan.

5. To find and verify the solution.

How someone fully understands physics. The student has to enrol in a university program in the field of physics because he (she) will be able to have many opportunities there. He will learn what he can't learn from books or the Internet, such as scientific research methods in physics, and ways to think about physical problems. He'll get to know people who specialize in physics, which will allow him to talk to them (whether they're professors or other students), the importance of these conversations is that he will face questions that he may not have foreseen. Also, he will listen to many points of view, and he will be able to learn multiple ways to access information. Fundamental physics is a broad term of science and contains many sections that must learn to understand physics well. Classical mechanics, among others, include linear \& rotational motion, Newton's laws, and the mechanics of Lagrange \& Hamilton. Electricity and magnetism which is concerned with the study of static and moving charges, the electrical and magnetic fields that arise from them, the relationship between them, as well as the study of electromagnetic waves (which contain visible light inside them), among others. Optics which are concerned with the study of optical phenomena (i.e., related to light); Thermodynamics is interested in studying the thermal interaction between objects. Statistical mechanics are interested in learning systems from a statistical point of view, as designs made up of a large number of items. Electronics contains diodes, coils, and capacitors. Special Theory of Relativity, it is interested in studying objects that move at very high speeds close to the speed of light. Ordinary quantum mechanics is considered one of the indispensable pillars of physics, which 
is interested in the study of quantum systems, focuses on the idea of muzzling very much. Astronomy is an integral part of our physics study, and it has a lot of exciting things that are large physical systems such as planetary motion, and Kepler laws (which are part of classical mechanics).

To study physics effectively, I advised my students of the importance of organizing time, and also writing notes during the lesson and rewrite them again at home. They must study in a quiet place using soft music or natural sounds and not songs with words. Students must read the article slowly and try to understand every word in the text before and after the class. The duties given in each category are essential, where the things that the teacher thinks are important. So the students must solve, study \& apply for exams so that they can measure their level and identify his weaknesses and disabilities to start addressing them. Writing summaries and doing some research is essential. It helps the student to understand the subject and save it more profound. Finally, the student must work hard because if he slackens and slows down in the performance of the work that he has to study or project or research assigned to him, he will not be able to learn and will certainly be doomed to failure (Krišták, Němec, \& Danihelová, 2014).

Physics studies open up a wide range for students to enter all disciplines. Physics offers the possibility of graduate studies in physics, engineering sciences, computer science, genetics, neuroscience, biology, atmospheric and ocean sciences, economics and finance, journalism and public policy sciences.

\subsection{Effective physics teaching skills}

For teaching physics effectively, I learned that the professional teacher has to perform his activities through fundamental and significant processes. He aims to help students to better teaching and learning, as it is one of the works that can be judged, on its quality and mastered through analysis and observation. Therefore after evaluation, one can improve and develop his performance. The method of teaching physics based on ease, accuracy and understanding of what a person acquires, and learns from a motor and mental point of view while providing a tremendous effort and costs. The physics teaching skill also defined as the teacher's act and his ability to create the required learning developed in several ways, such as educational preparation before the teaching process, knowledge of experiences and previous experiences in this subject. The variations of teaching skills depend on the nature of the teaching material taught to students, and the characteristics of the considered subject and their objectives. One must connect theory and practice (Redish \& Steinberg, 1999; Geelan, 2020).

There are three domains, the planning, the implementation, and the evaluation. The planning process is considered the first skill that a teacher who seeks excellence in his teaching process. It is a plan to be carried out by the teacher alone; he thinks about the subjects to be taught to students and how to perform them. The planning process requires teaching high capacity. The teacher must know the nature of the target group (learners) and understand their most essential needs, to make sure that they are present during teaching, and also determines the abilities and capabilities of these students to try to devote them, and to use them in the teaching process. The above is one of the essential inputs in the planning process, on which the teacher depends on his planning. After identifying these things, the teacher must be able to set the objectives of the educational process, analyze the content of the material to be taught, determine the best way to present the scientific material, and thus reach an elaborate plan for the lesson he will deliver. This plan should mention most important justifications in his use of educational objectives, as well as the sources of deriving from these objectives. The developed goals must be robust, precise and serve the educational process.

The execution of physics teaching skills includes the performed practices within the classroom. In section 3 , we present many other skills.

\section{Boot before lesson}

The teacher must establish a friendly relationship with the students to study and to participate in the science subjects.

\subsection{Pre-lesson preparation}

The pre-lesson preparation is the process aimed to make the student ready for the new lesson. The teacher must use all the words and actions so that the students are in a state of mind, and emotional lye that allows them to receive and accept the new information, and preparing the necessary skills. To view the lesson, the teacher must use a different process of preparing the course. This preparation is limited and focuses on the logical, emotional aspect of the students, their interest and making the orientation of students, and their feelings towards the scientific physics subject. After understanding these feelings, and the positive response to them, thus, the teacher will earn the friendliness and love of his students (Redish \& Steinberg, 1999). 


\subsection{The use of blackboard}

A blackboard is a tool of the teaching process, which helps the teacher to make him happy with the success of his educational work, and the use of the blackboard means integrating it into the educational process. If the teacher uses it optimally in the classroom, that is half of the lesson. The blackboard has many functions including, statement of terms, concepts, definitions of the course, and distance from the abstract character in the class that is bored of students, and the blackboard also helps to facilitate the explanation and analysis of the scientific material in the lesson, examples, and the use of additional drawings (Ball, 2017).

\subsection{The art of asking the question}

The art of asking questions in the classroom is the basis of the teaching process. It increases and deepens the process of thinking among students, through the meaningful questions used by the teacher, and to ask questions of great importance in improving the classroom atmosphere. The interspersed works, educational events, it adds an atmosphere of complimentary assistance. The bond between the teacher and his student so that the student is not just a recipient individual. He is a human being who receives information in a proper way, where he talks and discusses; he is in the classroom an active individual, interacting with the subject at hand (Vogt, 2003).

\section{Evaluation and assignments}

The homework placed by the teacher creates a kind of cooperation between the teacher and the student. The educators work together to make the educational process a success. Also, the students have a sense of responsibility towards themselves, attention to time and its value. The actions and statements made by the teacher help students to organize the information received in the class. It helps them to absorb more, and the closure is an activity complementary to the preparation of the lesson in an action started by the teacher. Still, closure is an activity that concludes the topics and shows the usefulness of the skill of closing in attracting the attention of students and guiding them to the end of the lesson. Develop data that can provide the level of students, and send reports to parents. Teaching is a science and art different views on the concept and what is teaching, whether education is an art, or is it science and art together, some of the educators believed that teaching is an art, and the students should surround the teacher. Knowledge to perform the teaching process, and there is no need to prepare the teacher and prepare it before the teaching process. Some others mention that teaching is based on a set of scientific foundations, a collection of research, specialized studies in education and psychology, and the third are that it is a profession that requires a set of skills, competencies that the teacher must master, and practice before the teaching process. In this sense, teaching became science and art at the same time (Permatasari, Istiyono, \& Kuswanto, 2019).

\section{The importance of physics teaching skill}

The necessity of teaching skill has emerged in many aspects, as the teacher's mastery of this skill facilitates the achievement of the objectives of the teaching process, facilitates the implementation of the work and tasks required. The ability of this skill deepens the process of teaching and learning, with increased awareness. Thus, the practice of the teaching process becomes very easy, and therefore the most significant achievements can be reached by the teacher and the students (Geelan, 2020).

\subsection{Characteristics of physics teaching skills}

Physics teaching skill is a form of effective teaching. It seeks to achieve specific objectives, graduating from the teacher in the form of behaviour associated with mental, verbal, motor or emotional responses, adapted accurately to the conditions of the teaching situation, and teaching skills possess many characteristics, most notably:

- General: The teacher's job is very similar at different stages of study and other physical subjects. Still, sometimes the change is like the attitude, which takes into account the age and the nature of the educational content.

- Change: It is possible that the teaching curriculum will change, and often associated with the conditions of society. The new teaching skills depend on the curriculum philosophy and the nature of students.

- Interaction: The nature of teaching attitude is complex; it is challenging to separate teaching behaviour so that skills are also difficult to separate from each other.

- Different performance method: There are undoubtedly behaviour patterns commonly used by teachers in the case of a particular skill, but this does not prevent differences between teachers, and this is related to their atti- 
tudes, and the effect of the method of applying the skill.

- Learning ability: Pre-service and skill acquisition subjected to four factors, including experience, motivation, execution, and practice. Types of teaching skills need to be practised, and trained after having prior information about them, in addition to a specific mechanism that demonstrates the skill within the behaviour, to stabilize them, and not forget them.

- The types of these skills are:

- Cognitive skills: Cognitive skills need a particular brain performance, used in the face of problems, or situations, that need solutions.

- Dynamic skills: Dynamic skills include motor performance, such as role-playing, writing, and action-needed activities.

- Planning: Planning is a scientific method through which practical measures are necessary to achieve future goals.

- Social skills: Social skills are related to the emotional nature of each teacher. Among the most prominent teaching skills are those that play an essential role in the teaching process. The most important of these skills are:

* Process students' answers, not ignore them, but should comment on them before moving on to a question, or another student.

* The teacher diversifies the excitement to attract the attention of the students during the lesson.

* The teacher prepares for the new lesson to make students ready for the new class.

* The teacher promotes and offers rewards to students for particular desirable attitude.

\section{Teaching physics and digital technology}

The fundamental principles of digital integration of educations are summarized as follows:

- Educational technology is not an alternative or an addition to teaching methods presented above.

- The use of education technology will contribute to the success of the education development strategy for the benefit of students.

- Students are increasingly advanced users of technology. So this can often mean being open to the possibilities presented to teach and prescribe the use of specific programs.

- Learning to be a global citizen is crucial in a world where technology is erasing borders.

Instead of struggling to give students all the information teachers need to succeed in areas they know little about it. Teachers can support students as they make their steps into different subjects. Digital education is about preparing students to go beyond their teachers, making sure they have the skills to do it, and then helping along the way as they build confidence to achieve. Teachers need to be forward-thinking, curious, and flexible (Euler, Gregorcic, \& Linder, 2020).

\subsection{Teachers must be learners}

Teachers must learn new ways alongside their students. In this concern, I asked: What will be the future of students? What kind of knowledge students will be after thirty or sixty years? How can teachers contribute to give students those skills and knowledge? How can teachers changing student mindset and making him a leader, and bringing changes in the classroom, and community? In this regard, I introduced five tasks that the teachers should do. These tasks are as follows:

- Teachers must invite students to contribute to strategy meetings and decision making to create adaptable learning environments suited to different sorts of collaboration and group work.

- Teachers must encourage students to take ownership of community service programs.

- Teachers must find ways to connect students to people of their age in other parts of the world,

- The teacher must review the use of technology in the classroom: how can it be made more effective? In a time when mental health and wellbeing is one of the biggest challenges facing young people, teachers can give students the skills they needed such as communication, critical thinking, and emotional intelligence beyond the workplace. They can help people through the most challenging times of their life.

Finding their passion, doing it well, having a sense of purpose and focus, and being able to control their work and life are all significant steps on the path to wellbeing. The ability to think critically and creatively, to collaborate with others, and to communicate sets students up for success in their careers, but also empowers them to lead happier and healthier lives. 


\section{Challenges of the physics quality teaching during Covid-19}

During the time of closing universities due to the sudden spread of Corona pandemic and the trend of countries to complete study programs via the Internet (Schröder-Turk \& Kane, 2020), many questions arose as follows:

- Did the closure of universities lead to the relaxation of faculty members and administrators from performing their duties?

- $\quad$ Did the online study run smoothly and effectively?

- What are the quality standards of the online education system, especially in the field of physics)?

- Did the online education system need to create new guidelines for designing appropriate curricula for online learning and monitor the performance of the teachers?

- There is no doubt that there are shortcomings of online learning in physics (as in many other fields) compared to face-to-face learning, such as the following:

- The lack of communication between students themselves and the teachers,

- The poor performance of the teacher, and his inability to supervise the quality of learning,

- The lack of practical training in the student laboratories,

- Unavailability of communication through internet networks,

- The lack of financial resources and capabilities to train teachers and students on the digital transformation of education.

- Students have difficulties in self-understanding in subjective ways of the physical concepts and theories.

In light of the crisis and trying to get out of it with the least losses, I raised the questioned concerning the quality of online education outcomes compared to face-to-face learning in physics education. In this respect, we need to think out of the ordinary bureaucratic routine to recognize, understand, and address these critical issues (Zaki Ewiss, 2020) and (Zaki Ewiss \& Afifi, 2020).

\section{Acknowledgement}

In light of these catastrophic events that no one can predict, I thank all officials, administrators and teachers at the Physics Department, Faculty of Science, Cairo University. They prompted decisions in response to these exceptional circumstances and the rapid transformation of online curricula, as well as the reaction of students and parents to these measures. We can say that these exceptional circumstances cannot continue and become a reality to change the education we know. Indeed, countries need graduates who can be responsible for their future development.

\section{References}

Ball, P. (2017). The Strange Link Between the Human Mind and Quantum Physics. http://www.bbc.com/earth/story/ 20170215-the-strange-link-between-the-human-mind-and-quantum-physics.

Ball, P. (2017). Education and Outreach Features: The Power of Blackboard. https://physicsworld.com/a/the-powerof-the-blackboard/.

Banik, I., Lukovičová, J., Pavlendová, G., Podoba, R. (2013). Problems In Teaching Physics At Technical Universities, Analele Universităţii de Vest din Timişoara Vol. LVII, 2013 Seria Fizică. DOI: 10.1515/awutp -2015-0102.

Bell, D. (2016). The reality of STEM education, design and technology teachers' perceptions: a phenomenographic study, Int J Technol Des Educ (2016) 26:61-79. DOI 10.1007/s10798-015-9300-9.

Calvin, S. (2013). A new approach to teaching physics. https://physicstoday.scitation.org /do/10.1063/pt.4.2440/full/.

Chassy, Ph., Jones, J. (2019). The role of mathematics in the learning of physics, Open Access Journal of Mathematical and Theoretical Physics, Vol. 2, 1. https://medcraveonline.com/OAJMTP/OAJMTP-02-00045.pdf.

Fields, G. S. (2010). Labor Market Analysis for Developing Countries. https://digitalcommons.ilr.cornell.edu/workingpapers/157.

Finkelstein, N. D. (2004). Teaching and learning physics: A model for coordinating physics instruction, outreach, and research. https://arxiv.org/ftp/physics/papers/0505/0505091.pdf/.

Freedman, R. A. (1996). Challenges in Teaching and Learning Introductory Physics, High-Temperature Superconductivity to Microminiature Refrigeration, B. Cabrera, H. Gutfreund, and V. Kresin, eds. (Plenum, New York), pp. 313-322. https://web. physics.ucsb.edu/ airboy/challenge.html.

ESC-Commission. (2011). On Labour, Income, Living Standards and Industrial Analysis on the Challenges Facing Labour Markets Within The Europe $2020 \quad$ Strategy, https://www.eesc.europa.eu/sites/default/files/resources/docs/ces-bg ---analysis-on-labour-market-within-2020_en.pdf. 
Euler, E., Gregorcic, B., Cedric Linder, C. (2020). Variation theory as a lens for interpreting and guiding physics students' use of digital learning environments, European Journal of Physics 41(4). DOI: 10.1088/1361-6404/ab895c.

Geelan, D. (2020). Physical Science Teacher Skills in a Conceptual Explanation, Educ. Sci., 10, 23; DOI:10.3390/educsci10010023.

Goldenfeld, N., Woese, C. (2011). Life is physics: Evolution as a collective phenomenon far from equilibrium, Annu. Rev. Condens. Matter Phys. 2, 375. DOI: 10.1146/annurev-conmatphys-062910-140509.

Gutulo, S. G., Tekello, K. O. (2015). Problems in the Teaching and Learning of Physics at the Secondary and Preparatory Schools, the Cases Wolaita and Dwuro Zones, Global Journal of HUMAN-SOCIAL SCIENCE: G Linguistics \& Education Volume 15, Issue 7, Version 1. https://globaljournals.org/GJHSS_Volume15/1-Problems-in-the-Teaching-and-Learning-of-Physics.pdf.

Krišsták, L., Němec, M., Danihelová, Z. (2014). Interactive Methods of Teaching Physics at Technical Universities, Informatics in Education, Vol. 13, No. 1, 51-71. https://www.researchgate.net/publication/278022612/.

Pawlak, A., Irving, P. W., Caballero, M. D. (2020). Learning assistant approaches to teaching computational physics problems in a problem-based learning course, Phys. Rev. Phys. Educ. Res. 16, 010139. https://journals.aps.org/prper/abstract/ 10.1103/PhysRevPhysEducRes.16.010139.

Pellegrino, J. W., Hilton, M. L. (Eds.) (2012). Education for Life and Work: Developing Transferable Knowledge and Skill in the 21st century, (The National Academies Press, Washington D. C.). https://hewlett.org/wp-content/uploads/ 2016/08/Education_for_Life_and_Work.pdf/.

Permatasari, A. K., Istiyono, E., Kuswanto, H. (2019). Developing an assessment instrument to measure physics problem solving skills for mirror topic. International Journal of Educational Research Review, 4(3), 358-366. https://dergipark.org.tr/tr/download/article-file/730426.

Redish, E. F., Steinberg, R. N. (1999). Teaching Physics: Figuring Out What Works, Physics Today, Vol. 52, pp. 24-30. http://www.physics.umd.edu/perg/qm/qmcourse/NewModel/research/whatwork/.

Schröder-Turk, G. E., Kane, D. M. (2020). How will COVID-19 change how we teach physics, post-pandemic? Phys Eng Sci Med, 43, 731-733. https://doi.org/10.1007/s13246-020-00896-x/.

Vogt, E. E. (2003). The Art Of Powerful Questions: Catalyzing Insight, Innovation, and Action, Whole Systems Associates, Homestead Boulevard, Mill Valley, CA. https://umanitoba.ca/admin/human_resources/change/media/the-art-of -powerful-questions.pdf.

Wright, K. (2019). Physics for Life, Physics 12, 2. https://physics.aps.org/articles/v12/2.

Zaki Ewiss, M. A. (2020). Capability determination of Educational Strategy, American Journal of Humanities and Social Sciences 6, 1-24. http://journalsonline.org/american-journal-of-humanities-and-social-science/pdfs/volume-6-issue-1/v6-i1-2.pdf.

Zaki Ewiss, M. A., Afifi, S. (2020). Capability Determination of Educational Management in Africa, Proceedings of The 2nd International Conference on New Approaches in Education. https://www.icnaeducation.org/abstract-2nd-round/80-879/. 